P-ISSN: 1978-7227 E-ISSN: 2615-3017

doi : https://doi.org/10.30598/barekengvol14iss3pp387-396

National Accredited in SINTA 3, Decree No.: 28/E/KPT/2019

\title{
PEMODELAN ARUS LALU LINTAS DAN WAKTU TUNGGU TOTAL OPTIMAL DI PERSIMPANGAN JL. JEMUR ANDAYANI AHMAD YANI SEBAGAI UPAYA MENGURAI KEMACETAN
}

\section{Modeling of Traffic Flow and Optimal Total Waiting Time at The Crossing of Jemur Andayani Ahmad Yani Street as an Effort to Unravel Congestion}

\author{
Yuniar Farida ${ }^{1 *}$, Aris Fanani ${ }^{2}$, Ida Purwanti ${ }^{3}$, Luluk Wulandari ${ }^{4}$, Nanida Jenahara Zaen ${ }^{5}$ \\ 1,2,3,3,4,5 Program Studi Matematika, Fakultas Sains dan Teknologi, UIN Sunan Ampel Surabaya \\ Jln. Ahmad Yani No.117, Surabaya, 60237, Indonesia \\ e-mail:1*yuniar_farida@uinsby.ac.id ; 2 arisfa@uinsby.ac.id ; ${ }^{3}$ idapurwanti111@gmail.com ; \\ ${ }^{4}$ lulukwulandari618@gmail.com ; ${ }^{5}$ nanidajz@gmail.com \\ Corresponding author*
}

\begin{abstract}
Abstrak
Salah satu persimpangan jalan di Surabaya yang memiliki tingkat kemacetan parah adalah persimpangan Jalan Jemur Andayani - Ahmad Yani. Dibutuhkan perbaikan dalam manajemen lalu lintas, geometrik serta waktu sinyal agar diperoleh kinerja lalu lintas yang optimal. Tujuan dari penelitian ini adalah mengembangkan pemodelan arus lalu lintas dan mengetahui waktu tunggu total optimal di persimpangan jalan Jemur Andayani - Ahmad Yani menggunakan Graf Kompatibel. Graf kompatibel merupakan dua buah himpunan dimana titik-titiknya menunjukkan objek-objek yang akan diatur (simpul/vertex) dan sisi-sinya (edge) menunjukkan pasangan objek yang sesuai (kompatibel). Arus lalu lintas yang kompatibel merupakan dua buah arus lalu lintas yang jika keduanya berjalan bersamaan dapat berjalan aman dan tidak bertabrakan. Hasil perhitungan waktu tunggu optimal menggunakan graf kompatibel dengan asumsi belok kiri mengikuti lampu adalah 75 detik. Sedangkan waktu tunggu total optimal dengan asumsi belok kiri tidak mengikuti lampu adalah 60 detik. Waktu tunggu total optimal tersebut lebih kecil dari waktu tunggu total aktual yang saat ini diterapkan di Frontage Jalan Ahmad Yani, yakni 170 detik dengan asumsi belok kiri mengikuti lampu.
\end{abstract}

Kata Kunci : graf kompatibel, Jl. Jemur Andayani-Ahmad Yani, waktu tunggu total optimal

\begin{abstract}
One crossroad of Surabaya whose high level of congestion is the crossing of Jemur Andayani - Ahmad Yani Street. It needs to Improve traffic management, geometric, and signal time to obtain optimal traffic performance. The purpose of this study is to make a model of traffic flow and determine the optimal total waiting time at the crossing of Jemur Andayani - Ahmad Yani using Compatible Graph. Compatible graphs are two sets where vertices indicate objects to be arranged and edges indicate compatible pairs of objects. Compatible traffic flow is two traffic flows which if both of them run simultaneously can run safely and not collide. The results of the optimal waiting time calculation using a compatible graph assuming the left turn following the lamp is 75 seconds. While the optimal total waiting time by assuming the left turn not following the lights is 60 seconds. The optimal total waiting time is smaller than the actual total waiting time currently applied at Frontage Ahmad Yani street, which is 170 seconds by assuming turn left following the lights.
\end{abstract}

Keywords: Compatible Graph, optimal total waiting time, Jemur Andayani-Ahmad Yani crossroad 


\section{PENDAHULUAN}

Indonesia merupakan salah satu negara yang populasi kendaraannya terus meningkat tiap tahunnya. Berdasarkan data Badan Pusat Statistik (BPS) pertahun 2017 jumlah kendaraan di tanah air mencapai 138.556.669 unit [1] [2]. Angka tersebut mencakup mobil penumpang, bus, mobil barang, kendaraan khusus dan sepeda motor. Hal ini membuat kemampuan ruas jalan untuk menampung arus atau volume lalu lintas yang ideal dalam satuan waktu tertentu semakin berkurang. Surabaya merupakan salah satu kota dengan jumlah penduduk yang padat. Terlihat pada bulan Januari 2019 berdasarkan data dari Dinas Kependudukan dan Catatan Sipil (Disependukcapil) populasi penduduk Surabaya berjumlah 3.095.026 jiwa [3] [4]. Hal tersebut disebabkan karena kedudukannya sebagai ibukota Provinsi Jawa Timur yang merupakan kota terbesar kedua setelah Jakarta. Selain itu, adanya beberapa Universitas ternama di Surabaya memacu para pelajar dari luar kota untuk menimba ilmu disana. Banyak pula orang dari luar kota yang menghabiskan masa hidupnya untuk mencari nafkah disana karena melihat banyak peluang baik dari sektor jasa, barang maupun industri. Hal ini mengakibatkan populasi penduduk di Surabaya akan terus bertambah pesat. Dampaknya, makin banyak permintaan lahan sebagai tempat pemukiman atau tempat usaha. Di sisi lain diikuti pula peningkatan permintaan akan kendaraan pribadi (terutama kendaraan bermotor). Dengan berkurangnya lahan kosong, meningkatnya populasi kendaraan, serta akses jalan raya yang tidak berubah, membuat terjadinya kemacetan dimana-mana.

Salah satu persimpangan jalan di Surabaya yang memiliki tingkat kemacetan parah adalah persimpangan jalan Jemur Andayani - Ahmad Yani. Berdasarkan penelitian yang dilakukan oleh [5] menyebutkan bahwa dalam persimpangan tersebut, harus dilakukan perbaikan dalam manajemen lalu lintas, geometrik serta waktu sinyal agar diperoleh kinerja lalu lintas yang optimal. Kemacetan di persimpangan jalan tersebut terjadi karena simpangan tersebut merupakan akses pergi atau pulang bagi mahasiswa dan civitas akademik dari UINSA serta bagi pekerja yang berasal dari kawasan Rungkut Industri dan sekitarnya. Selain itu, persimpangan Jemur Andayani ini juga menghubungkan ke arah jalan nasional yaitu jalan Ahmad Yani yang juga dilintasi jalur kereta api sehingga kemacetan yang terjadi di persimpangan ini menimbulkan peningkatan waktu tunggu yang begitu lama. Waktu tunggu merupakan waktu yang dibutuhkan seseorang untuk menunggu di persimpangan jalan sebelum lampu hijau menyala [6] [7]. Tersendatnya arus lalu lintas di persimpangan ini sering terjadi pada jam-jam sibuk yaitu pada waktu pagi hari dan sore hari.

Persimpangan jalan merupakan salah satu kawasan yang sangat rawan dengan kecelakaan. Dalam mengatasi hal tersebut, salah satu cara yang digunakan adalah dengan memasang lampu lalu lintas. Pada dasarnya, tujuan dari pemasangan lampu lalu lintas di persimpangan jalan adalah untuk mengatur pergerakan suatu kendaraan dengan kendaraan lainnya agar dapat bergerak secara bergantian tanpa saling mengganggu satu sama lain [8] [9] [10]. Lampu lalu lintas yang digunakan sebagai sumber pengendali yang ada di jalan tentunya harus mempertimbangkan situasi serta kondisi dari persimpangan jalan [11]. Beberapa komponen yang menjadi pertimbangan terkait situasi serta kondisi persimpangan jalan Jemur Andayani Ahmad Yani antara lain volume kendaraan, geometrik simpangan, serta adanya jalur rel kereta api. Disamping itu, adanya waktu tunggu yang kurang seimbang di kedua jalur tersebut sering menyebabkan menumpuknya kendaraan di jalur tertentu dan diperparah dengan kurang tertibnya pengendara dalam mematuhi lampu lalu lintas (pengendara di dua jalur tersebut saling berebut untuk melintas) sehingga perlu dikembangkan alternatif penyelesaian model arus lalu lintas dan waktu tunggu total optimal yang ada di persimpangan jalan tersebut.

Graf Kompatibel merupakan salah satu kajian ilmu pengetahuan yang digunakan secara umum untuk menyelesaikan permasalahan dengan melibatkan pengaturan data dalam urutan tertentu [12] [13] [14] [15]. Arus lalu lintas dikatakan kompatibel ketika dua buah arus lalu lintas dapat berjalan bersamaan tanpa ada gangguan satu sama lain sehingga aman dan tidak saling berpotongan. Oleh karena itu, penelitian ini menggunakan graf kompatibel sebagai model dalam menentukan waktu tunggu total optimal di persimpangan jalan Jemur Andayani - Ahmad Yani sebagai upaya untuk mengurai kemacetan lalu lintas.

Beberapa penelitian dilakukan oleh [9] [16] [17] [18] [19] [20] menggunakan Graf Kompatibel untuk memecahkan masalah manajemen arus lalu lintas dan penentuan waktu tunggu total optimal di berbagai persimpangan jalan. 


\section{METODE PENELITIAN}

\subsection{Teknik Pengumpulan Data}

Metode pengumpulan data yang digunakan dalam penelitian ini adalah dengan metode observasi. Data primer yang dikumpulkan adalah jumlah jalur, arus lalu lintas dan waktu tunggu pada persimpangan Jalan Jemur Andayani - Ahmad Yani. Arus lalu lintas yang diamati adalah ketika lurus dari arah Utara menuju Selatan dan lurus dari arah Timur menuju ke Barat. Adapun lokasi penelitian ditunjukkan oleh Gambar 1 berikut:

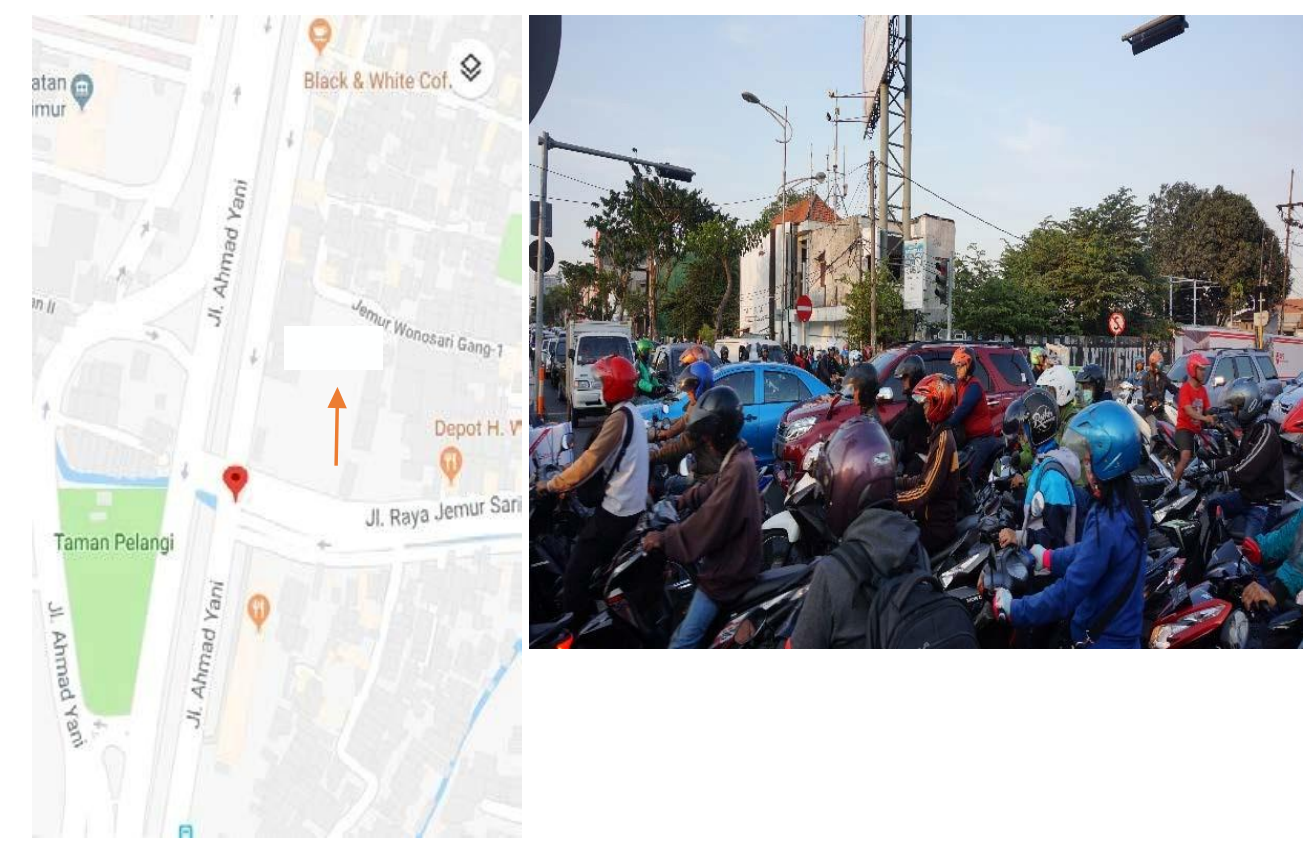

Gambar 1. Peta lokasi obyek penelitian, persimpangan jalan Jemur Andayani -

Ahmad Yani ditandai dengan simbol location yang berwarna merah (gambar kiri). Kemacetan yang sering terjadi di persimpangan jalan Jemur Andayani-Ahmad Yani (gambar kanan)

Untuk pengambilan data penelitian dilakukan pada pagi, siang, dan sore pada tanggal $22-24$ Juli 2019 dengan melakukan observasi langsung di lapangan. Berikut asumsi yang digunakan:

a. Penelitian ini dilakukan dengan mengamati tiap ruas jalan dari dua arah simpang tiga Jalan Jemur Andayani - Ahmad Yani.

b. Data waktu tunggu lampu lalu lintas yang digunakan adalah :

1) Pagi hari pada pukul 06.00 - 08.00 WIB, dengan asumsi banyaknya pekerja dan pelajar yang berangkat beraktivitas pada jam tersebut.

2) Siang hari pada pukul 12.00-14.00 WIB, dengan asumsi banyaknya pelajar yang pulang beraktivitas pada jam tersebut.

3) Sore hari pukul 16.00-18.00 WIB, dengan asumsi banyaknya pekerja yang pulang beraktivitas pada jam tersebut.

4) Pada penelitian ini mengabaikan jumlah kendaraan dan kondisi ketika kereta api melintasi kawasan tersebut.

\subsection{Prosedur Pengolahan Data}

Penelitian ini menggunakan Teori Graf Kompatibel dalam memodelkan arus lalu lintas dan menentukan waktu tunggu total optimal. Teori graf merupakan cabang dari ilmu Matematika yang sudah ada sejak lebih dari 200 tahun silam. Teori graf pertama kali muncul pada tahun 1736 yang membahas masalah jembatan Koningsberg, oleh matematikawan dari Swiss yang bernama Leonardo Euler [21] [22]. Suatu Graf $G$ didefinisikan sebagai himpunan $\{\mathrm{V}, \mathrm{E}\}$ dimana $V$ adalah himpunan tidak kosong dari simpul atau vertex $=\left\{v_{1}, v_{2}, v_{3}, \ldots, v_{n}\right\}$ dan $E$ adalah himpunan sisi (edge) yang menghubungkan simpul atau vertex $E=\left\{e_{1}, e_{2}, e_{3}, \ldots, e_{n}\right\}$. 
Graf Kompatibel merupakan graf yang simpul dan sisinya menunjukkan suatu pasangan dari objek yang kompatibel (sesuai) [23]. Adapun prosedur pengolahan data pada penelitian ini adalah sebagai berikut:

a. Menggambarkan graf kompatibel dimana titik-titiknya (vertex) menunjukkan arus lalu lintas yang akan diatur dan sisi-sisinya (edge) menunjukkan pasangan objek yang kompatibel. Gambar 2 merupakan contoh persimpangan jalan [24].

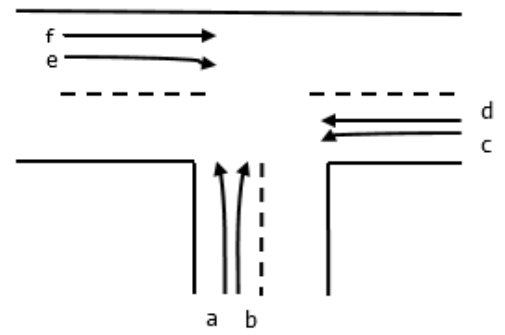

Gambar 2. Persimpangan Jalan

Arus lalu lintas yang terdapat pada persimpangan jalan di atas dikatakan kompatibel. Artinya, arus tersebut dapat berjalan dalam waktu yang bersamaan tanpa saling membahayakan. Dalam persimpangan jalan tersebut, arus $a$ berkompatibel dengan arus $b, c, d$, e dan $f$. Kemudian arus $b$ kompatibel dengan arus $a, c$ dan $f$, dan seterusnya. Arus lalu lintas pada persimpangan jalan tersebut dapat dibentuk dalam graf kompatibel, yang disajikan pada Gambar 3 berikut. [25]

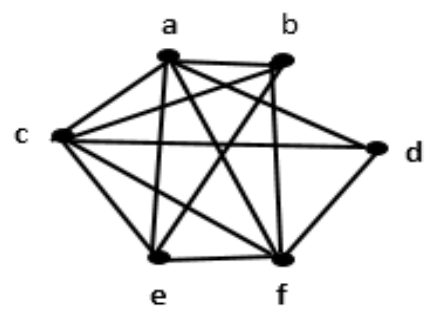

\section{Gambar 3. Graf Kompatibel Arus Lalu Lintas pada Persimpangan Jalan}

b. Menentukan subgraf lengkap terbesar.

Subgraf yang dimaksud adalah menunjukkan arus lalu lintas mana saja dari suatu jalur yang berkompatibel dengan arus lalu lintas lainnya.

c. Menentukan waktu siklus setiap arus lalu lintas berdasarkan banyaknya subgraf lengkap dengan cara membagi satu periode waktu dari jumlah banyaknya subgraf lengkap terbesar. Kemudian mengalikan hasil waktu siklus setiap arus lalu lintas dengan masing-masing titik subgraf lengkap. Salah satu cara mengatur lampu lalu lintas sehingga terbentuk suatu arus lalu lintas yang kompatibel yaitu menggunakan diagram jam. Gambar 4 merupakan contoh penyelesaian pengaturan dengan diagram jam.

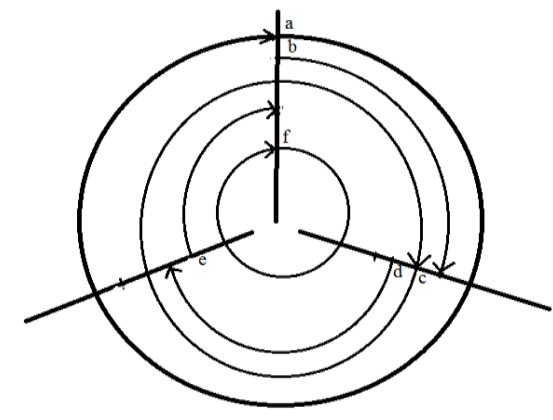

Gambar 4. Pengaturan Diagram Jam

Jika lampu lalu lintas beroperasi selama 60 detik putaran, maka arus $a, c$, dan $f$ dapat berjalan selama 60 detik, sedangkan arus $b, d$, dan $f$ dapat berjalan selama 20 detik. 
d. Menentukan waktu tunggu total. Waktu tunggu total dihitung dengan menjumlahkan semua hasil dari perkalian antara waktu siklus tiap arus lalu lintas dengan masing-masing titik subgraf lengkap. Dari Gambar 3 dapat diperoleh waktu tunggu total optimal selama $(3 \times 60)+(3 \times 20)=240$ detik.

e. Menghasilkan pemodelan arus lalu lintas dan waktu tunggu optimal menggunakan graf kompatibel pada persimpangan Jalan jemur Andayani - Ahmad Yani.

\section{HASIL DAN PEMBAHASAN}

\subsection{Sistem Arus Lalu Lintas di Persimpangan Jalan Jemur Andayani - Ahmad Yani}

Setelah dilakukan observasi di lapangan, diperoleh data waktu tunggu lampu lalu lintas di persimpangan Jalan Jemur Andayani - Ahmad Yani sebagaimana ditunjukkan Tabel 1.

Tabel 1. Lama Siklus Waktu Awal Lampu Lalu Lintas Pada Persimpangan Jl. Jemur Andayani - Ahmad Yani

\begin{tabular}{cccc}
\hline No. Lampu & Merah (detik) & Kuning (detik) & Hijau (detik) \\
\hline Lampu I & 132 & 3 & 58 \\
\hline Lampu II & 72 & 3 & 118 \\
\hline Lampu III & 76 & 3 & 107 \\
\hline Lampu IV & 170 & 3 & 20 \\
\hline Lampu V & 95 & 3 & 139
\end{tabular}

Dari hasil pengamatan yang telah dilakukan dalam waktu yang berbeda yaitu pagi, siang dan sore hari menunjukkan bahwa siklus lampu lalu lintas pada persimpangan Jalan Jemur Andayani - Ahmad Yani sama. Hal tersebut sebenarnya tidak efesien, dikarenakan berdasarkan jumlah atau kepadatan kendaraan yang melintas pada waktu pagi, siang dan sore hari berbeda. Selain itu, terdapat pula waktu tunggu yang tidak seimbang membuat terjadinya penumpukan kendaraan pada sisi Frontage Jl. Ahmad Yani.

Berikut ini sistem lalu lintas yang diterapkan pada persimpangan Jalan Jemur Andayani-Ahmad Yani dapat dilihat pada Gambar 5.

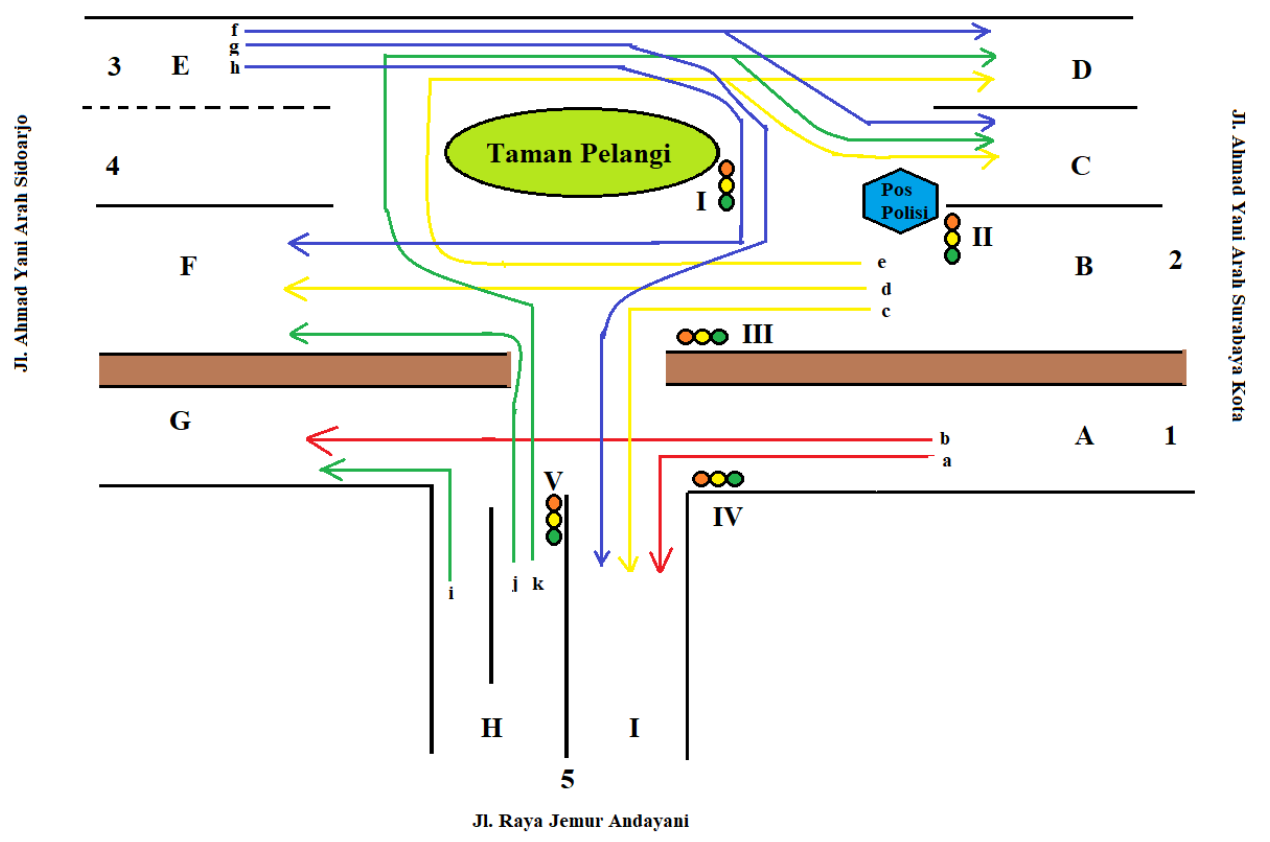

Gambar 5. Sistem Lalu Lintas pada Persimpangan Jalan Jemur Andayani - Ahmad Yani

\section{Keterangan :}

1. Frontage Jl. Ahmad Yani Arah Surabaya Kota

4. Jalur utama Jl. Ahmad Yani arah Sidoarjo

2. Jalur utama Jl. Ahmad Yani Arah Surabaya Kota

3. Frontage Ahmad Yani Arah Sidoarjo

5. Jl. Raya Jemur Andayani

Untuk notasi A, B, C, D, E, F, G, H, dan I merupakan titik-titik lintasan di persimpangan tersebut. Sedangkan untuk $a, b, c, d, e, f, g, h, i, j, k$ dan $l$ menunjukkan arus lalu lintas dari masing-masing jalur. 


\subsection{Pemodelan Graf Kompatibel Arus Lalu Lintas Persimpangan Jalan Jemur Andayani - Ahmad Yani}

Arus lalu lintas dapat dikatakan kompatibel apabila kedua arus berjalan bersamaan tidak menghasilkan kecelakaan. Dari siklus lampu lalu lintas di persimpangan Jl. Raya Jemur Andayani - Jl. Ahmad Yani dibentuk model graf kompatibel seperti yang terlihat pada Gambar 6.

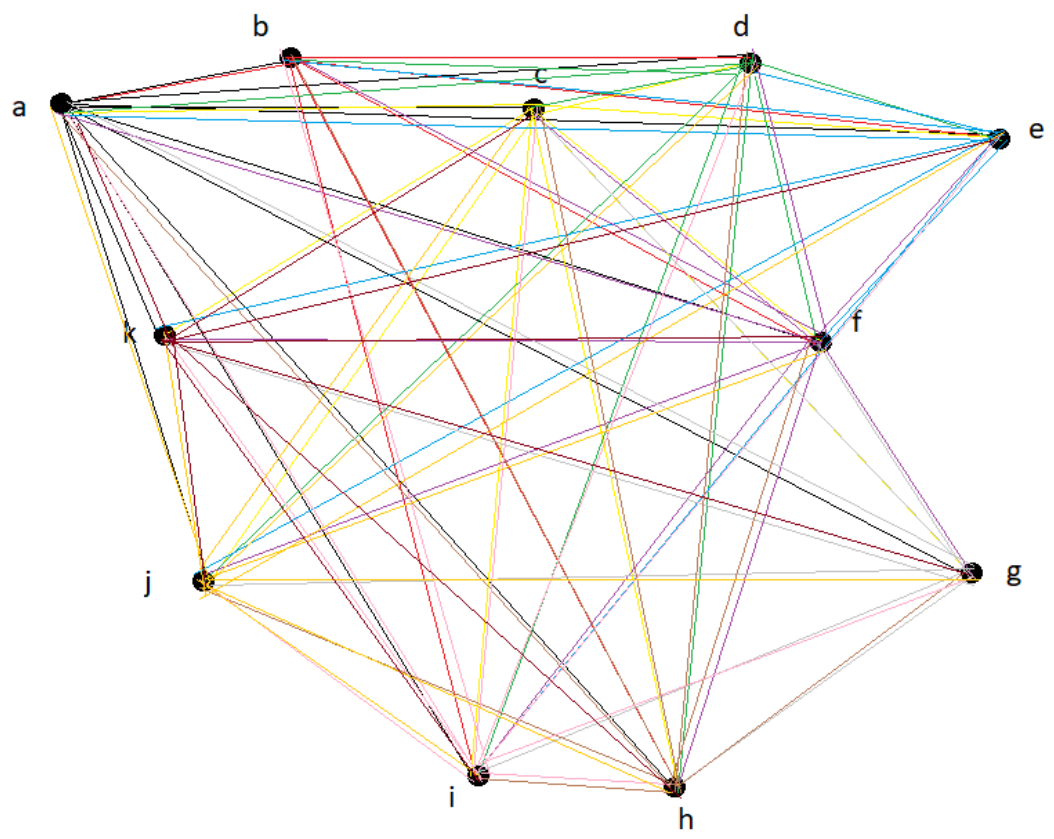

Gambar 6. Bentuk Graf Kompatibel pada Persimpangan Jl. Raya Jemur Andayani - Jl. Ahmad Yani

dimana jalur $a$ kompatibel dengan semua titik ,Titik $b$ kompatibel dengan jalur $a, d, e, f, h$ dan $I$. Jalur $c$ kompatibel dengan $a, c, d, e, f, g, h, i, j$ dan $k$, Jalur $d$ kompatibel dengan jalur $a, b, c, e, f, h, i$ dan $j$. Jalur $e$ kompatibel dengan Jalur $a, b, c, d, f, i, j$ dan $k$. Jalur $f$ kompatibel dengan semua Jalur. Jalur $g$ kompatibel dengan Jalur $a, c, f, h, i, j$ dan $k$. Jalur h kompatibel dengan Jalur $a, b, c, d, f, g, i$ dan $j$.

\subsection{Penerapan Graf Kompatibel Untuk Menentukan Waktu Tunggu Optimal}

Dalam menentukan waktu tunggu total optimal di persimpangan Jalan Raya Jemur Andayani - Jalan Ahmad Yani dibagi menjadi dua asumsi yaitu asumsi belok kiri mengikuti lampu dan belok kiri tidak mengikuti lampu.

a. Asumsi belok kiri mengikuti lampu rambu-rambu lalu lintas

Sistem lalu lintas dengan asumsi belok kiri mengikuti lampu lalu lintas didasarkan pada sistem arus lalu lintas yang ada (eksisting) sebagaimana ditunjukkan pada Gambar 5 sebelumnya.

Selanjutnya sistem lalu lintas pada Gambar 5 dimodelkan ke dalam bentuk subgraf lengkap yang dapat ditunjukkan pada Gambar 7.

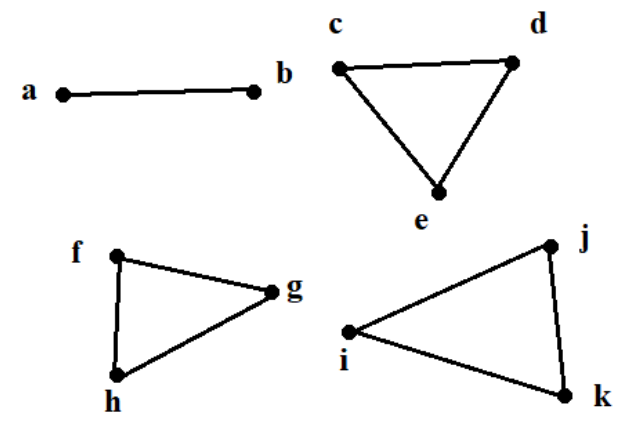

Gambar 7. Subgraf dengan Asumsi Belok Kiri Mengikuti Lampu Lalu Lintas 
Keempat subgraf lengkap pada Gambar 7 tersebut memuat 3 titik dan 2 titik. Sehingga dapat divisualisasikan dalam diagram jam sebagaimana ditunjukkan pada Gambar 8.

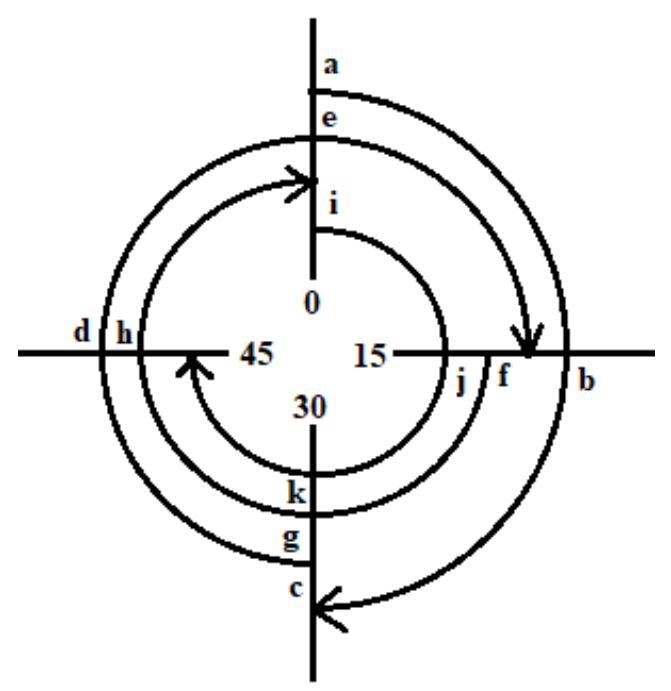

Gambar 8. Diagram Jam dengan Asumsi Belok Kiri Mengikuti Lampu Lalu Lintas

Dengan mengasumsikan lampu lalu lintas beroperasi selama 60 detik tiap putaran maka salah satu penyelesaiannya adalah membiarkan setiap arus berjalan selama 60 detik : 4 subgraf lengkap $=15$ detik. Karena dalam subgraf lengkap terdiri dari 3 dan 2 titik yang terbentuk maka setiap periode 60 detik, arus dari tiap jalur berjalan selama $3 \times 15=45$ detik dan $2 \times 15=30$. Karena terdapat 5 titik pada subgraf lengkap diatas maka untuk waktu tunggu total optimalnya adalah $5 \times 15$ detik $=\mathbf{7 5}$ detik.

b. Asumsi belok kiri tidak mengikuti lampu rambu-rambu lalu lintas

Sistem lalu lintas dengan asumsi belok kiri tidak mengikuti lampu lalu lintas berbeda dengan system lalu lintas yang ada saat ini (eksisting). Sistem tersebut dapat digambarkan sebagai berikut:

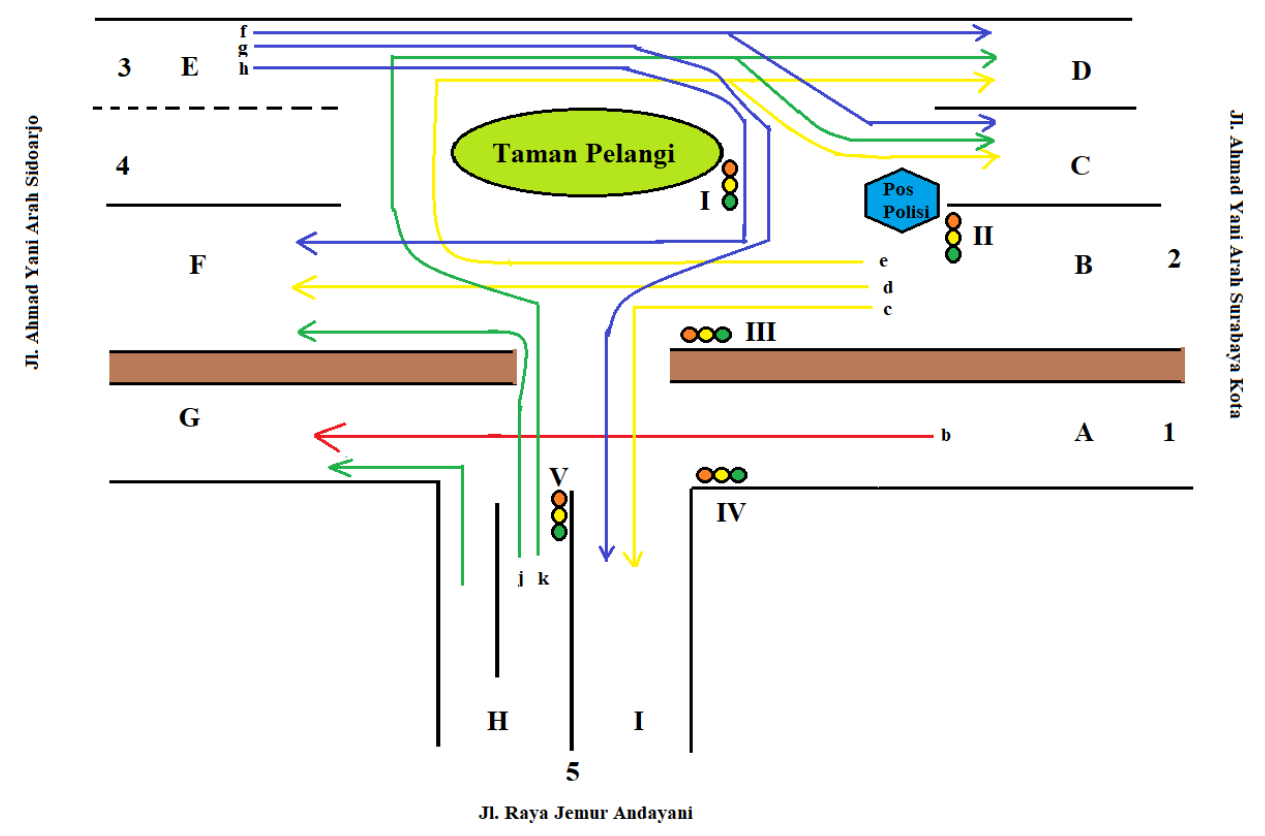

Gambar 9. Siklus waktu lampu lalu lintas Saat Belok Kiri Tidak Mengikuti lampu Lalu Lintas

Selanjutnya sistem lalu lintas pada Gambar 9 dimodelkan ke dalam bentuk subgraf lengkap yang ditunjukkan pada Gambar 10 sebagai berikut. 


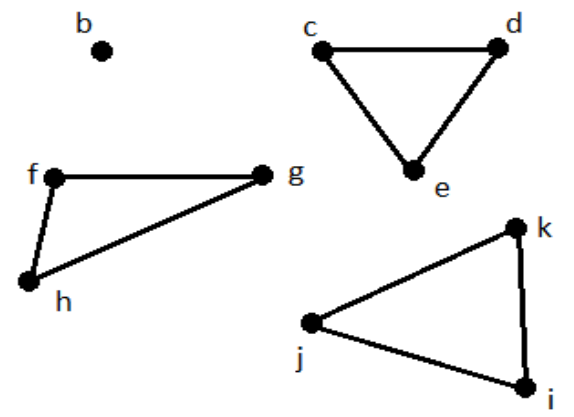

Gambar 10. Subgraf dengan Asumsi Belok Kiri tidak Mengikuti Lampu Lalu Lintas

Keempat subgraf lengkap pada Gambar 10 tersebut memuat 3 titik dan 1 titik. Sehingga visualisasi dalam diagram jam ditunjukkan pada Gambar 11 berikut.

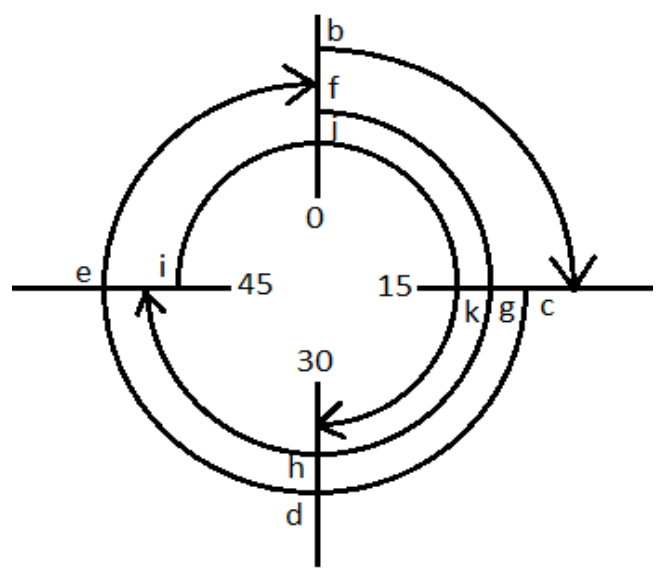

Gambar 11. Diagram Jam dengan Asumsi Belok Kiri Tidak Mengikuti Lampu Lalu Lintas

Karena dalam subgraf lengkap terdiri dari 3 titik dan 1 titik yang terbentuk maka setiap periode 60 detik, maka arus dari tiap jalur berjalan selama $3 \times 15=45$ detik dan $1 \times 15=15$ detik. Karena terdapat 4 titik pada subgraf lengkap diatas maka untuk waktu tunggu total optimalnya adalah $4 \times 15$ detik $=\mathbf{6 0}$ detik.

\subsection{Pembahasan}

Berdasarkan Gambar 5 berikut perbandingan waktu tunggu total yang telah diterapkan dan waktu tunggu total optimal menggunakan graf kompatibel.

Tabel 2. Perbandingan Waktu Tunggu Setelah dan Sebelum Menggunakan Graf Kompatibel

\begin{tabular}{lcc}
\hline No Lampu & $\begin{array}{c}\text { Waktu Tunggu di Lapangan } \\
\text { (detik) }\end{array}$ & $\begin{array}{c}\text { Waktu Tunggu dengan Graf Kompatibel } \\
\text { (detik) }\end{array}$ \\
\hline Lampu I & 132 & 75 \\
\hline Lampu II & 72 & 75 \\
\hline Lampu III & 76 & 75 \\
\hline Lampu IV & 170 & 60 \\
\hline Lampu V & 95 & 75 \\
\hline
\end{tabular}

Dari Tabel 2 di atas, waktu tunggu total yang diterapkan saat ini pada Frontage Jl. Ahmad Yani ke arah Sidoarjo dan ke arah Rungkut (Lampu IV) adalah 170 detik dengan asumsi belok kiri ke arah Rungkut mengikuti lampu. Dengan menggunakan graf kompatibel, dengan skenario yang sama (yakni belok kiri ke arah Rungkut mengikuti lampu) dihasilkan waktu tunggu total optimal yang lebih singkat yakni sebesar 75 detik. Namun jika asumsinya belok kiri tanpa mengikuti lampu lalu lintas, didapatkan waktu tunggu yang lebih singkat lagi, yakni 60 detik. Sejatinya jika dilihat dari waktu tunggu yang dihasilkan graf kompatibel, skenario yang lebih optimal adalah dengan membiarkan arus lalu lintas yang belok kiri ke arah Rungkut langsung belok tanpa mengikuti lampu lalu lintas. 


\section{KESIMPULAN}

Graf Kompatibel digunakan secara luas dalam memecahkan masalah yang melibatkan pengaturan data dalam tata urutan tertentu. Graf Kompatibel merupakan graf yang simpul dan sisinya menunjukkan suatu pasangan dari objek yang kompatibel (sesuai). Dalam penelitian ini, graf yang titik-titiknya menunjukkan objek-objek yang akan diatur, dan sisi-sisinya menunjukkan pasangan objek yang kompatibel (sesuai). Adapun bentuk graf kompatibel dari hasil pemodelan arus lalu lintas pada persimpangan jalan Jemur Andayani - Jalan Ahmad Yani sebagaimana ditunjukkan pada Gambar 6. Dengan menerapkan graf kompatibel, diperoleh hasil perhitungan waktu tunggu optimal dengan asumsi belok kiri mengikuti lampu sebesar 75 detik. Sedangkan waktu tunggu total optimal dengan asumsi belok kiri tidak mengikuti lampu sebesar 60 detik. Waktu tunggu tersebut lebih singkat daripada yang diterapkan oleh DLLAJ saat ini.

\section{UCAPAN TERIMA KASIH}

Terimakasih kami sampaikan kepada UIN Sunan Ampel Surabaya atas pemberian Dana Bantuan Penelitian Tahun 2019 melalui SK Rektor No. 330 Tahun 2019.

\section{DAFTAR PUSTAKA}

[1] B. P. Statistik, "Perkembangan jumlah kendaraan bermotor menurut jenis," Senin November 2017. [Online]. Available: www.BPS.go.id. [Accessed Senin November 2019].

[2] Atmaja and N. Insani, "Pengoptimalan sistem arus lalu lintas menggunakan pemodelan graf kompatibel (studi kasus persimpangan jembatan baru UGM)," Jurnal Matematika, vol. 05, no. 01, pp. 1-7, 2016.

[3] Aini, "Awal tahun 2018, Dispendukcapil predikat jumlah warga pendatang di surabaya tak ada lonjakan," Selasa November 2018. [Online]. Available: Tribunjatim.com. [Accessed Senin November 2019].

[4] S. Basriati and S. Wahyuni, "Teori graph dan implementasinya dalam ilmu komputer," Sains Matematika dan Statistika, vol. 02, no. 01, pp. 1-7, 2016.

[5] C. Rahmawati and D. Novitasari, "Evaluasi kinerja lalu lintas simpang bersinyal Jl. Ahmad Yani-Jemur Andayani dengan adanya frontage road surabaya," Institut Teknologi Sepuluh Nopember, Surabaya, 2013.

[6] E. Budi and Sunarsih, "Masalah rute terpendek pada jaringan jalan menggunakan lalu lintas," Jurnal Matematika dan Komputer, vol. 06, no. 01, pp. 59-70, 2013.

[7] M. Riana, "Model antrian waktu tunggu kendaraan di persimpangan lampu lalu lintas condong catur dengan compound poisson arrivals dan memperhatikan sisa antrian sebelumnya," Universitas Negeri Yogyakarta, Yogyakarta, 2014.

[8] D. Hardianti, "Penerapan graf kopatibel pada penentuan waktu tunggu total optimal di persimpangan jalan kaligarang kota semarang," UNNES Journal of Mathematics, vol. 02, no. 01, pp. 1-8, 2013.

[9] A. Fanani, "Optimasi waktu tunggu lampu lalu lintas dengan menggunakan graf kompatibel sebagai upaya mengurangi kemacetan," SYSTEMIC, vol. 02, no. 01, pp. 45-50, 2016.

[10] Sutrisno, "Aplikasi graf dalam rekayasa perangkat lunak," MUARA, vol. 01, no. 01, pp. 315-327, 2017.

[11] AASHTO, Apolicy on geometric design of highways and street, Washington DC, 2007.

[12] Wilson and J. Watskin, Graph Introductory Approach, 1976.

[13] S. Tanvee, "Application of graph theory for scheduling of traffic lights," International Journal of Mathematics and Computer Application Research, vol. 03, no. 01, pp. 271-275, 2015.

[14] K. M and Taufiqurrochman, "Pemanfaatan aplikasi graf pada pembuatan jalur angkot 05 Tasikmalaya," Seminar Nasional dan Teknologi, vol. 05, no. 01, pp. 1-6, 2017.

[15] R. Munir, Matematika Diskrit, Bandung: Informatika, 2001.

[16] I. Roza, "Graf garis (line graph) dari graf siklus, graf lengkap dan graf bintang," Matematika UNAND, vol. 03, no. 02, pp. 1-4, 2014.

[17] A. K. Baruah, "Traffic control problem using graph connectivity," International Journal of Computer Application, vol. 86, no. 11, pp. 1-3, 2014.

[18] A. K. Baruah, "Signal groups of compatible graph in traffic control problem," International Journal of Advance Networking and Application, vol. 04, no. 01, pp. 1-3, 2012.

[19] Hosseini and Orooji, "Phasing of traffic light at a road junction," Applied Mathematical Science, vol. 03, no. 30, pp. 1-8, 2009. 
[20] R. Johnsonbaugh, Discrete Mathematics revised edition, New York: Maemillian Publishing Company, 1986.

[21] Wirdasari, "Teori graph dan implementasinya dalam ilmu komputer," SAINTIKOM, vol. 10, no. 01, pp. 23-34, 2011.

[22] I. Budayasa, Teori graf dan aplikasinya, Surabaya: UNESA University Press, 2007.

[23] H. Sutarno, Common text book matematika diskrit, Jakarta: Universitas Pendidikan Indonesia, 2003.

[24] A. K. Baruah, "Intersection graph in traffic control problem," International Journal of Mathematics and Computer Application Research, vol. 03, no. 01, pp. 265-270, 2013.

[25] D. Dave and N. Jhala, "Application of graph theory in traffic management," International Journal of Engineering and Inovative Technology, vol. 03, no. 12, pp. 124-126, 2014. 